\title{
TEAM TEACHING AN INTERDISCIPLINARY COURSE: LESSONS LEARNED
}

\author{
Donna C.S. Summers, George A. Bohlen \\ The University of Dayton
}

\begin{abstract}
The diverse technical and management issues in today's business environment demand interdisciplinary, system-oriented approaches. To cope with the increasing complexity of these situations, companies are turning to cross-functional teams. Participants of interdisciplinary teams who readily understand the backgrounds and viewpoints of the other members enhance the effectiveness of these teams.

Educational institutions, unlike business, continues to educate students within particular functional areas. While education serves many purposes, including stimulating students to acquire and utilize knowledge to think critically, from a more practical viewpoint, education should assist students in developing skills applicable to their future careers. To prepare graduates for work in an interdisciplinary environment, crossfunctional courses should be developed at the undergraduate level to expose students to the types of interdisciplinary problem-solving and team activities they will encounter in industry.
\end{abstract}

At the University of Dayton, the Department of Industrial Engineering Technology in the School of Engineering and the Department of Management Information Systems and Decision Sciences in the School of Business Administration worked together to structure a course combining business and engineering technology viewpoints, concepts and students. Careful consideration was given to select a course which, when taught cross-disciplinary, would enhance students' ability to apply course information effectively in a business environment. The interdisciplinary course combined courses titled, Quality Management, from the Industrial Engineering Technology program and Total Quality Management from the School of Business Administration. This particular interdisciplinary course was developed because managing people, processes, and information from a quality view point requires an understanding of all facets of the organization. Having decided upon the course, the decision was made to team teach the course to ensure that the students were exposed to quality management concepts from both a business and an engineering perspective. This paper provides insights into the creation of such a course and the lessons learned from team teaching an interdisciplinary course. The lessons learned concerned logistics and administrative issues, course preparation and course conduct.

\section{Introduction}

The development of this interdisciplinary team taught course had its roots in a discussion held by several faculty members during graduation exercises. The discussion centered on the problems associated with exposing students to all of the different viewpoints that come into play while making business decisions. Courses in Engineering and in Business, with their current structure, were essentially isolated silos of information. If this is the case, then how do students become prepared for working in today's business 
environment where a variety of people from all areas of the company get together and make decisions concerning the future of the business?

Through the efforts of these faculty members and others, work began on creating an interdisciplinary course in a topic appropriate to both business and Engineering. Faculty members from several different areas of study and individuals from industry were invited and encouraged to attend the course development team meetings. Eventually the core participants were from the Department of Industrial Engineering Technology, the Department of Management Information Systems and Decisions Sciences, and industry. Several key areas became the focus of these meetings: which course, the structure of the course, the personalities and fortes of the potential teachers, the needs of industry, the logistics of offering such a courses, and the willingness of the administration to support the cross-functional effort.

\section{The Course}

The course development meetings revealed several courses in Engineering and in Business that were candidates for combining into an interdisciplinary course. Two courses appearing the most in common were the Industrial Engineering Technology course, Quality Management, and the Decision Sciences course, Total Quality Management. Since quality improvement activities are often interdisciplinary in nature, these courses were chosen as the basis for the new interdisciplinary course.

The course prerequisites included production-operations topics such as just-in-time manufacturing, inventory control and statistical process control. The course had a heavy emphasis on a "process" orientation of the enterprise rather than a functional orientation. Included were topics on the quality gurus such as Deming and Juran, business process re-engineering, continuous quality improvement concepts, and activitybased-cost accounting. Students were divided into teams consisting of both business students and engineering students to accomplish two major projects. One project consisted of flow charting the processes in the University Bursar's office. The students had to flow chart the existing process and recommend improvements. As a term assignment, each student team was required to contact a local firm, interview representatives from all levels of management and evaluate the firm against each of the Malcolm Baldrige National Quality Award Criteria. Each student team was required to orally present their findings from the Bursar's office project and to present their conclusions concerning the Baldrige Award project both in a formal written report and in a formal oral presentation.

The designing of the course required students from both disciplines to discuss topics that would normally be associated with only one discipline. For example, the Baldrige criteria addresses both operational processes and business processes. Activity-based-cost accounting is an excellent way to examine a firm form a "process" orientation and focus on the actual costs of designing and producing a product. Also, ISO 9000 requirements address product design, manufacturing and other issues appropriate to both engineering and non-engineering disciplines. The use of interdisciplinary teams resulted in students examining items appropriate to both engineering and business.

Interestingly enough, following the selection of the course, through the use of input from each program's industrial advisory committees, the needs of industry and the topics and structure of the new course were the most easily identified. Determining the appropriate combination of faculty members, ironingout the logistics of offering the course, and obtaining administration support were more difficult. 


\section{LESSONS LEARNED}

\section{Logistics and Administrative Lessons Learned}

As with any newly offered course, the logistics issues can range from problem-free to exceedingly complex. Coordinating the schedules of two faculty members, while meeting the teaching load requirements of two unrelated departments, requires forethought. Administrative difficulties with class numbering, course sequencing, pre-requisites, program degree requirements, an classroom allocation were encountered. While the concept of team-teaching is encouraged at the University of Dayton, the administrative policies are not in place to cope with a team taught interdisciplinary course. Rather than redesign policies, rules and regulations, the course development team held brainstorming sessions to discover the best methods to circumvent the variety of barriers that threatened to prevent the course from being offered. To accommodate teaching load requirements of both departments, the course was actually offered in two sections in back-to-back time slots. In both time slots, the course was double numbered, with one number for engineering technology students and one for business students. It was necessary to offer the course in the Spring of 1995 in two time slots, with two course numbers, and with limited enrollment for each course number (engineering and business) to ensure that an appropriate mix of students from each major signed up for the class. This type of schedule, though a strain for those teaching the class, also reduced the complexities of course waivers for graduation requirements and allowed for meeting faculty teaching load requirements. To add to the feeling that this experience would treat information from both majors with the same emphasis, a classroom on neutral ground in the Humanities building was chosen in order to prevent anyone taking the course from associating it strongly with one major or the other.

From our experience at the University of Dayton an important lesson to learn is to have the support of the relevant department chairs, deans, and ultimately the administration. A second lesson to learn is to be creative when finding ways around the barriers preventing success.

\section{Team Teaching Lessons Learned: Preparation}

During the sessions held to create the course, those potentially teaching the course as a team spent time getting to know each other and discovering each other's areas of interest and teaching styles.

Participants attended each other's classes to observe the other's style as well as to serve as guest speakers. The two individuals eventually chosen by the course development team to teach the course had relatively similar teaching styles but different areas of interest in quality. As the term progressed it became apparent that having compatible teaching styles provided the course with greater continuity. This revelation came from the students who expressed a need to have a cohesive courses. One of their most frequently given comments on informal and formal teaching evaluations expressed a need to have compatible teaching styles.

A second lesson learned about team teaching is the importance of having teaching schedules and a detailed syllabus for the term worked out in advance. This, too, became a significant benefit of the course because coordinating topic coverage was facilitated by the detailed schedule. There was little doubt as to who would be teaching on a particular day and what topic they would be covering. If a professor happened to miss the lecture provided by his/her team-mate, the syllabus combined with pre-lecture discussions provided a smooth transition from one professor to another.

We strongly encourage all participants in a team teaching experience to attend as many of the classes taught by other team members as possible. Having all team members present reinforces the integration of the disciplines. Providing a cohesive class is only possible if you have a very good 
understanding of what the other presenters said about related topics. Sporadic or non-attendance when a team member is not officially teaching the class leads to a course taught by two or more people and does not meet the original goal of an integrated, inter-disciplinary course.

\section{Team Teaching Lessons Learned: Student Feedback}

To gain the most from a team teaching experience, it is important to receive timely input from the teacher's key customers: the students. Encourage a lot of feedback from the students throughout the term. Establishing informal feedback mechanisms throughout the term provides an outlet for the students to express their concerns, impressions, and ideas for improvement. We also maintained an open door policy and encouraged students to visit us to discuss the course. Anytime students visited our offices, they were asked to comment on the course. After receiving the input from the students, we discussed it and made changes to the course if possible. Receiving and reacting to student feedback helped lessen the difficulties inherent in having two professors. Waiting until the formal teaching evaluations at the end of the term would not have provided some of the information which was used to strengthen the course while it was being taught. Without the feedback from the students, those participating in this team teaching experience would not have known how important having compatible teaching styles is to the students. Several other of the lessons learned have come directly from informal student input.

Even with the complexities of team teaching, the students saw the different knowledge base, background and experience of the two professors as a factor which strengthened and enhanced the course. Had they had only one professor, they would not have benefited from the broader knowledge base.

\section{Team Teaching Lessons Learned: Interdisciplinary and Integrated}

Care should be taken to create a link between the lectures given by one professor and the other. Informal and formal student evaluations clearly pointed to this factor as the one item which distracted from student learning. Each professor should briefly review the topic covered in the previous class period, regardless of which professor was the primary teacher for that particular class. The professor should then provide a transition from the topics covered in the previous class period to the topics to be covered in the current class period and show how they relate to each other. While it is probably a good idea to do this in any class, it is very important in a "team taught" course to reinforce the smooth transition from one professor to another and to reinforce the integration of the material in the course.

A team taught course should be just that: team taught. An important lesson to learn is that professors should regularly attend each others classes or at the very least meet regularly to ensure course coordination. According to their evaluations, students felt professors must work diligently to integrate and coordinate their lectures. As mentioned before, the professors could see distinct advantages to attending each others classes. Meeting outside of class to structure the syllabus is important but true integration can only occur if both professors are in class to add insight to the topic under discussion. Of course this will require the mutual respect of the faculty participants to ensure that no one faculty member becomes the dominant participant. For this particular experience, an agreement was made beforehand to participate in class only if the lead professor for that topic asks for comment. Comments by other team members can disrupt the flow of thought of the lead professor, as well as the flow of the lecture and the flow of student learning. Speaking only when asked to comment creates a less confusing learning environment for the students. They are better able to separate points of view and determine what information is critical. 
Another critical aspect of limiting the number of comments made by teachers other than the lead professor for the topic is being sure to give the appearance of a unified viewpoint for the topic under discussion. While divergent and differing points of view are necessary, unless they are handled in an organized fashion, they have the potential of sending mixed signals to the students. If several different viewpoints exist and are related to the interdisciplinary nature of the topic, then those teaching the course can meet beforehand to determine how to present the opposing views in an organized fashion.

Form interdisciplinary teams and choose an interdisciplinary term project. The selection of an interdisciplinary project and the formation of interdisciplinary teams allows students from multiple disciplines to share their points of view with each other in a project format. During the term project, students from different programs have the opportunity to determine the specialties and strengths of those areas. This information will be invaluable in industry where team members need an understanding of the functions performed by those from different business areas.

Presenting unified positions to the students is important not only from a lecture standpoint, but also from an assignment and grading point of view. Team teaching experiences, especially the first time they are encountered, are confusing for the student. Those teaching the course can increase the comfort level for their students and thus enhance learning, by ensuring that their lecture topics are integrated, the assignments are linked to the lectures, and that the course expectations are clearly spelled out. As those team teaching the Quality Management course quickly found out, this can be easier said than done.

Students encountering their first experience with team teaching are concerned about who will be grading the assignments and tests. They have a valid need for course expectations which are clearly spelled out in the syllabus. To provide the students with this information, the professors teaching the course must agree on and have a clear understanding of what constitutes satisfactory and unsatisfactory student work for each assignment. Consistency in grading is particularly crucial for a team teaching situation. Be sure to clearly communicate to the students what is expected for each assignment. Interestingly enough, having to clearly delineate what should be graded and how for each assignment in the team-taught-class improved the style of communicating expectations in the other courses that each professor taught.

Even though project due dates were worked out in advance, technical difficulties as well as students' requests for changes caused the best laid plans to go astray. Flexibility is key in any learning experience and maintaining that flexibility in two classes with two teachers is relatively complex. An important lesson learned from this teaching experience is to have project due dates worked out in advance and make no changes to those due dates without consulting the other team teacher. When making changes, be sure to inform all participants in writing of the changes.

When determining who will grade the papers and how grading will be handled, we first began by having professors grade assignments related to their lectures. This was effective for smaller assignments, but as the assignments became more interdisciplinary, we formalized a grading system more reflective of the activities in the class. Assignments and test questions were graded independently by each professor. Completing this step, the professors then met to compare grades and determine the final grade for the assignment. While this approach took more time, it more closely resembled the interdisciplinary nature of the assignments and the course. 


\section{BENEFITS}

\section{Students}

Formal feedback was received from the students at the end of the course. In addition, informal feedback was received during the course, at the end of the course and during the semester following the course. This feedback indicated that the students perceived the following benefits. They gained valuable experience working on interdisciplinary teams. They learned to approach business problems in an interdisciplinary manner. They gained a mutual respect for the knowledge, skills, abilities and viewpoints of the students in each discipline. They gained first hand knowledge of the complexities of engaging in crossfunctional efforts. They learned to adjust to two instructors in one course, each representing a different discipline but teaching the course in an integrated manner.

\section{Instructors}

The most significant benefits achieved by the faculty participants in this experience were the insights, inputs and feedback concerning teaching styles, methods, and materials. Participating in a team teaching situation was like having a teaching consultant and friend to share information with. Having a partner to serve as a sounding board provided courage to try new ideas. The team teaching experience has the potential to modify, strengthen and improve teaching methods.

\section{SUMMARY}

Team teaching an interdisciplinary course to engineering and business students can be a rewarding learning experience for both the students and the instructors. Adapting to such a course requires some adjustments on the part of both the students and the instructors. The course described here was designed by instructors from engineering technology and business as well as representatives from industry. The course focused on Quality Management in an organization and addressed both business and engineering issues. Topics relevant to both business students and engineering students stressing the interdisciplinary nature of business problems were presented and discussed. Students were required to work in interdisciplinary teams on two major projects in the course. One of the projects required the students to conduct an interdisciplinary study in a company in the local area and to develop a written report and make a formal oral presentation of their findings. The instructors learned to work together to design the course, prepare for teaching the course, conduct the course, and make improvements for the next offering. The evaluation of the course resulted in a number of lessons learned to assist the instructors and others in offering similar courses in the future.

1. Carrabine, Laura, "Concurrent Engineering: Narrowing the Education Gap," CAE, vol. 10, No. 10, October 1991, pp. 90-94.

2. Collison, Michele N-K, "Learning Communities' for All”, Chronicle of Higher Education, Vol. 40, No. 12, November 10, 1993, p. A18.

3. Gailey, Joan D., "Toward a Collaborative Model for Interdisciplinary Teaching: Business and Literature," Journal of Education for Business, Vol. 69, No. 1, September 1993, pp. 36-39.

4. Hill, William T., "Curriculum Integration and Interdisciplinary Teaching in a Business School Setting: Dilemmas for Faculty," Education, Vol. 11, No. 3, Spring 1990, pp. 313-318. 
5. Mansuy, John E., "A Different View of Management Account in Business and Education," Industrial Engineering, Vol. 25, No. 4, April 1993, pp. 66-69.

6. Newstrom, John W., "The Dynamics of Effective Team Teaching," Personnel Administrator, Vol. 26, No. 7, July 1981, pp. 55-58, 64.

7. Parson, Stephan R., "Program Development, Team Instruction and the Impact on Faculty Members," NASSP Bulletin, Vol. 78, No. 559, February 1994, pp. 62-64.

8. Potocki, Kenneth, "How TQM Works in a University Classroom," Journal for Quality \& Participation, Vol. 17, No. 1, January - February 1994, pp. 68-77.

9. Souders, John C., "Power of Ten - A Model of an Interdisciplinary Capstone Course for the Basic Sciences," Journal of College Science Teaching, Vol. 22, No. 5, March 1993, pp. 295-598

DONNA C.S. SUMMERS is a Professor in the Mechanical, Industrial and Manufacturing Engineering Technology Department at the University of Dayton. Her major areas of concentration are quality assurance and human factors. She studied at Purdue University and received her Doctorate in Industrial Engineering from the University of Cincinnati. Her text, Quality, is published by Prentice-Hall.

GEORGE A. BOHLEN is an Associate Professor in the Department of MIS and Decision Sciences in the School of Business Administration at the University of Dayton. His primary teaching interests are in production/operations in the undergraduate business program and the MBA program.. 